\title{
Regularities, Natural Patterns and Laws of Nature
}

\author{
Stathis PSILLOS
}

Received: 22.04 .2013

Final version: 16.10 .2013

BIBLID [0495-4548 (2014) 29: 79; pp. 9-27]

DOI: $10.1387 /$ theoria. 8991

ABSTRACT: The goal of this paper is to outline and defend an empiricist metaphysics of laws of nature. The key empiricist idea is that there are regularities without regularity-enforcers. Differently put, there are natural laws without law-makers of a distinct metaphysical kind. This outline relies on the concept of a 'natural pattern' and more significantly on the existence of a network of natural patterns in nature. The relation between a regularity and a pattern will be analysed in terms of mereology. Here is the road map. In section 2, I briefly discuss the relation between empiricism and metaphysics, aiming to show that an empiricist metaphysics is possible. In section 3, I offer arguments against stronger metaphysical views of laws. Then, in section 4,1 motivate nomic objectivism. In section 5 , I address the question 'what is a regularity?' and develop a novel answer to it, based on the notion of a pattern. In section 6, I analyse the notion of pattern and in section 7 I raise the question: 'what is a law of nature?', the answer to which is: a law of nature is a regularity that is characterised by the unity of a natural pattern..

Keywords: laws of nature; regularities; empiricism; metaphysics; pattern.

RESUMEN: El objetivo de este artículo es plantear y defender una metafísica empirista sobre las leyes de la naturaleza. La idea empirista clave es que hay regularidades sin que se requiera la existencia de algo que haga que se mantengan como tales (regularity-enforcers). Dicho de otro modo, hay leyes naturales sin que lo que produce la ley (law-maker) pertenezca a una categoría metafísica diferente. Este plan se apoya en el concepto de "esquema natural" (natural pattern) y en la existencia de una red de esquemas naturales en la naturaleza. La relación entre una regularidad y un esquema se analizará en términos mereológicos. Explico la ruta que seguiré. En la sección 2 discuto brevemente la relación entre empirismo y metafísica con objeto de mostrar que una metafísica empirista es posible. En la sección 3 doy argumentos contra concepciones de las leyes más metafísicas. Después, en la sección 4, apoyo el objetivismo nómico. En la 5 abordo la pregunta ‘qué es una regularidad?' y desarrollo una respuesta novedosa, basada en la noción de esquema. En la sección 6 analizo la noción de esquema y en la 7 planteo la cuestión ‘¿qué es una ley de la naturaleza?’, cuya respuesta es: una ley de la naturaleza es una regularidad que se caracteriza por la unidad de un esquema natural.

Palabras clave: leyes de la naturaleza; regularidades; empirismo; esquema.

${ }^{*}$ Earlier versions of this paper have been presented at: the workshop 'Explanation, Causality and Unification', University of Dusseldorf, November 2011; the University of Konstanz, February 2012; the workshop 'Metaphysics of Science', College de France, May 2012; and the workshop 'The Metaphysics of Scientific Realism', University of Athens, March 2013. Many participants helped me with comments and criticism. They know who they are and I thank them all wholeheartedly. Two anonymous readers of Theoria offered me generously detailed comments and the points made by one of them helped me clarify my views substantially. Research for this paper was co-financed by the European Union (European Social Fund - ESF) and Greek national funds through the Operational Program "Education and Lifelong Learning" of the National Strategic Reference Framework (NSRF) - Research Funding Program: THALIS - UOA-APRePoSMa. 


\section{Introduction}

I take it that it is fact that there is regularity in nature. What's controversial is the question whether there are any further grounds for this fact. There have been two major philosophical stances towards this question.

(1) This fact is basic-ultimately: a cosmic accident, which is not (and need not be) amenable to a metaphysically deeper/more robust explanation.

(2) This fact is not ultimate; it is grounded on regularity-enforcers: these constitute a metaphysically distinct (and deeper) layer of entities (and further facts about them) which enforce the existence and operation of regularities; they ensure their presence and-more importantly — their future extendability.

Empiricists endorse (1) but deny (2). Rationalists-typically, but not invariably-took it that powers are the required regularity enforcers. ${ }^{1}$

The goal of this paper is to sketch an empiricist metaphysics of laws of nature. The key idea is that there are regularities without regularity-enforcers. Differently put, there are natural laws without law-makers of a distinct metaphysical kind. And yet, natural laws are robust and objective enough! This sketch will rely on the concept of a natural pattern and, more significantly, on the existence of a network of natural patterns in nature. The relation between a regularity and a pattern will be analysed in terms of mereology.

There are a number of reasons why the proposed conception of laws as those regularities that are characterised by the unity of a natural pattern is preferable to a perhaps naïve regularity view of laws. But there are also a number of reasons why a regularity view of laws is preferable to presumably more robust accounts of lawhood. Part of the paper will offer these reasons.

Here is the road-map. In section 2, I briefly discuss the relation between empiricism and metaphysics, aiming to show that an empiricist metaphysics is possible. In section 3, I offer arguments against stronger metaphysical views of laws. Then, in section 4, I motivate nomic objectivism. In section 5, I address the question 'what is a regularity?' and develop a novel answer to it, based on the notion of a pattern. In section 6, I analyse the notion of pattern and in section 7 I raise the question: 'what is a law of nature?', the answer to which is: a law of nature is a regularity that is characterised by the unity of a natural pattern.

\section{Empiricism and Metaphysics}

Before I proceed in earnest, I will try to get out of the way (or at least quieten) a preliminary worry that some readers might have, viz., how can the project I am engaged in be in line with empiricism, since it looks for a metaphysics of laws?

\footnotetext{
${ }^{1}$ Though, I do not intend in this paper to make a historically accurate and precise claim, I think there is a lot of historical evidence for this way to read (at least a good part of the difference between empiricism and rationalism. Current occupiers of these two stances do not (and need not) associate their views with the two traditions. In fact, as it will be clear later on, there is resistance to powers even by some philosophers who deny that the existence of regularity in nature is a basic (unexplained) fact.
} 
Empiricism may well be seen as placing limits to the aspirations of Reason in providing substantive knowledge of the world independently of experience. As I have argued elsewhere, ${ }^{2}$ insofar as we are entitled to consider the various historical and conceptual versions of empiricism as a philosophical view with a common form, the form should be broadly epistemological and methodological: empiricism is an approach to how knowledge is acquired and evaluated; knowledge is acquired from experience and is evaluated by experience. But if empiricism is an epistemological-cummethodological view, it has no deep metaphysical implications, in and of itself.

'Metaphysics', it should be noted, is a term of art. It might be taken to be the general framework of ontological categories that, arguably, is required for a unified and coherent conception of the structure of the world-where this conception is not licensed directly by the scientific image of the world, but is presupposed by it. Viewed this way, metaphysics deals with basic entities (such as universals and particulars, or substances and attributes) as well as relations (such as causation) that are supposed to constitute the deep structure (the skeleton, one might say) of the world. Alternatively, metaphysics might be taken to deal with a supersensible realm of beings and principles (such as God, soul and determinism). Empiricism, in and of itself, does not entail a certain ontology, and various empiricists have subscribed to various ontological frameworks (though some of them might be more 'congenial' to empiricism than otherse.g. nominalism). But there is still a felt tension between empiricism and metaphysics, captured nicely by Russell $(1956,272)$ when he said: "By metaphysical entities I mean those things which are supposed to be part of the ultimate constituents of the world, but not to be the kind of thing that is ever empirically given". If various metaphysical posits are not empirically given, how can they be known? How then is metaphysical knowledge possible?

This is a familiar question, especially after Kant. He, actually, took empiricism not to be outright anti-metaphysical, but to place limits on metaphysics, by placing understanding on its "own proper ground", viz., the field of genuinely possible experiences (A468/B496). Hence, he took it that empiricism is based on a "maxim" which recommends bumility. As Kant put it, empiricism recommends "moderation in the pretensions of reason and modesty in its affirmations". But this modesty does not imply scepticism, since, according to Kant, empiricism, "at the same time", directs us "to the right mode of extending the province of the understanding, by the help of the only true teacher, experience".

The key issue for the relation between empiricism and metaphysics, I claim, is the status of metaphysical theory. How are metaphysical theories justified? If we put the question like this, the anti-metaphysical trend in empiricism is best seen as a reaction to a certain way in which metaphysical theories are justified, viz., by the lights of reason only. Opposing this, one need not argue against metaphysics viewed as providing ontological frameworks. It is enough to argue against a priori theorising as a (the?)

2 In my Cardinal Mercier Lectures delivered at the Catholic University of Louvain, Louvain-la-Neuve in March 2013; see especially my inaugural lecture: "Empiricism and scientific realism: on the ancient roots of a modern debate". 
way to get to these frameworks. So an empiricist need not deny that metaphysical theorising is possible. Rather, she would have to propose an alternative way to do it and to justify it. ${ }^{3}$ The good news, as Quine has made clear, is that if there is no clear and sharp distinction between science and metaphysics, the issue of metaphysical theorising tends to be absorbed by the issue of scientific theorising. So the question 'What kind of evidence, if any, is there for a metaphysical theory?' becomes part of the question 'What kind of evidence, if any, is there for a scientific theory of the world?'. There are various delicate issues to be dealt with - such as the possible underdetermination of metaphysical theories by scientific ones. But this is not something that makes metaphysical theorising impossible, unless it also does scientific theorising impossible.

The preliminary point, then, I want to drive home is that the form of empiricism I intend to defend is not outright anti-metaphysical. It opposes speculative a priori metaphysical theorising and in particular a conception of metaphysics as a body of allegedly a priori principles about the ultimate causes of worldly facts.

To give some concrete content to the kind of empiricism I want to defend, I place it within a broadly (neo)-Humean perspective to reality, which we may usefully take it to involve the following three negative theses:

A. There are no necessary connections between distinct and separate existences (No entailment enforcers).

B. There are no universals as distinct from classes of resembling particulars (No resemblance enforcers).

C. There are no powers as distinct from their manifestations (No regularity enforcers).

It may be debated whether or not these principles are part of empiricism, but they are surely consistent with empiricism. These principles aim to block certain ways to develop metaphysical accounts of the world. That is, they aim to restrict the scope of metaphysical theories of the world. But they should be taken with some caution. They do not imply that there are no resemblances in nature, or co-occurrences of events, or even activity in nature. Rather, they put a ban on certain ontologically inflated attempts to explain or ground all these things. They oppose a certain categorical framework for understanding the world and explaining the regularity there is in it, viz., a framework which is based on the triplet: necessity; universals; powers. ${ }^{4}$ More con-

${ }^{3}$ For a development of the way logical empiricists tried to do metaphysics, see my (2011).

4 Let me note that there are two ways to conceptualise 'powers'. The one is ontologically innocuous and is related to the common claim that entities do things in virtue of their properties, under certain circumstances. In this sense, it is commonsensical to say that water has the power to dissolve salt, and the like. This way of talking about powers does not commit someone to the view that powers are essentially dispositional, are involved in necessary connections with other powers, are directed towards their manifestations even when they are not exercised, exist (in some irreducible sense) even if they are not being exercised, are not ultimately grounded in non-powers etc. Hence, an ontologically thick conception of powers is not the direct consequence of the foregoing ordinary way to accommodate talk about powers in everyday life and in science. Rather, an ontologically thick way to conceptualise 
cretely, the empiricism I want to defend opposes a certain combination of these ontic categories, according to which powers, qua universals involved in necessary connections among themselves and with their manifestations, enforce regularities in the world.

These three principles have been typically motivated by epistemological considerations, viz., that the alleged knowledge of the required enforcers goes well beyond what can be known on the basis of experience as well as of scientific method. But I want to highlight that the defence of these principles is based on the application of Ockham's razor, in the sense of the principle that there is no need to posit an explainer, if explanation can proceed without it or if the call for explanation can be coherently deflected.

Besides these negative theses, I take it that there is also a positive element in the empiricist approach I want to defend: it advocates a sparse metaphysical view of the world, according to which there are irreducible regularities in nature (regularities all the way down, so to speak) which involve patterns of dependence among members of natural classes (natural properties) and which underpin the causal and generally modal relations there are between them.

I call this a regularity-based metaphysics. And the issue that I want to focus on is the conception of laws of nature that is suitable for this kind of empiricist metaphysics. Accordingly, the sought after conception of laws of nature should be such that it is

a) tied to the presence of regularities;

b) hence, it is metaphysically light-weight; but

c) robust enough to be able to ground at least some of the features/functions attributed to laws in scientific practice (e.g. their role in explanation; the fact that they support of counterfactuals).

\section{Nomic Necessitation Revisited}

The very idea that laws are characterised by some kind of necessity was meant to draw a sharp distinction between supposedly genuine laws of nature and accidentally true generalisations (what were taken to be mere regularities). But what kind of necessity is this? Tackling this issue, William Kneale (1949, 79), argued that laws of nature are "principles of objective necessitation". He thought there was a difference between the necessity of some generalisations and the contingency of others, and he took necessity to be "a boundary to possibility" (1949, 78). But how is possibility bounded? Kneale's examples were cases such as "the incompatibility of redness and greenness" $(1949,80)$.

Though the foregoing example might suggest a kind of conceptual necessity, Kneale was clearly trying to canvass a notion of nomological necessity which is not logical or conceptual; viz., a notion of necessity which would not imply that laws would be known a priori. Yet, his attempts came to grief mostly because most philosophers took him to imply that the sought after nomological necessity, qua necessity, should be

powers is a metaphysical theory about powers and their nature. The kind of empiricism I want to defend opposes to this thick theory and not to ordinary talk about properties and powers. 
tied to a priority. A. J. Ayer (1963, 213-4) expressed the then prevailing view that an obvious consequence of the approach that laws hold with necessity is that "they are purely logical truths" and hence that "they must be discoverable by reason alone". Given the extra premise that all laws of nature are known only from experience, Ayer $(1963,214)$ suggested that "there could not be any such relation [of necessary connection] not as a matter of fact but as a matter of logic".

The split that followed Kneale's aborted attempt to introduce a strong notion of nomological necessity — one that enforces some regularities to be laws-cut very deep. On the one hand, there are those philosophers who are motivated by the intuition that laws are contingent (that is that they are not metaphysically necessary) and conceive of law-making as an external relation among properties such that some properties bave to be co-instantiated in the actual world, but not in all possible worlds. On the other hand, there are those who think that some substantive notion of nomological necessity can be safeguarded only if the contingency intuition is abandoned altogether, that is only if the law-making relation is internal to the properties involved in a law, in that, given the (nature of the) properties, their co-instantiation is necessitated in all possible worlds.

Let us briefly review these two approaches. The first view—defended by David Armstrong, Fred Dretske and Michael Tooley—takes laws to be relations of necessitation among properties (qua universals). The key feature is that a novel relation of nomic necessitation is posited — typically symbolised by $\mathrm{N}$ - which is a (second-order) relation among first-order universals. $N$ itself is a (higher-order) universal-the repeatable and recurring feature shared by all laws of nature. It is in virtue of standing in the $\mathrm{N}$-relation to each other that some properties instantiate a law. A law-statement is typically written as $N(F, G)$, meaning: F-ness necessitates $G$-ness, or being $F$ necessitates being $G$. But though two properties $F$ and $G$ might stand in the $N$-relation in the actual world, there might not stand in the $N$-relation in any other possible world. $N$ is an $e x$ ternal relation in the sense that it does not supervene on the first-order universals and their properties, though as it happens it does relate certain universals in the actual world. Still, the claim is that $N$ is robust enough to relate F-ness and G-ness in the actual world in such a way that insofar as there is a regularity of the form $\mathrm{R}(=\mathrm{All}$ Fs are Gs), $R$ is entailed by $N(F, G)$. So $N$ is what I call an 'external regularity enforcer'.

There are well-known problems with this view, ${ }^{5}$ but for the present purposes, one really stands out. $N$ is taken to be a contingent relation; yet, it (is supposed to) entail(s) the corresponding regularity R. What kind of entailment this is remains obscure. It is not metaphysical entailment, because this would be too strong. If it's taken to be a


in all possible worlds of kind $\mathrm{K}$ ), then we need some restriction on the kind $\mathrm{K}$ of possible worlds in which this holds, and it is not clear at all what this restriction might be, apart from a restriction to the actual world. But then, the entailment is a kind of material implication. It's no longer clear, then, what - in the actual world-distinguishes between laws and accidents. Unless some regularity of the form R: All Xs are Ys is al-

${ }^{5}$ I have discussed them in detail in my (2002, chapter 5). 
ready taken to be accidental, some (perhaps mundane and low-level) nomic relation of necessitation between being $\mathrm{X}$ and being $\mathrm{Y}$ can be concocted such that it is true in the actual world that 'if N(X, Y) then R: All Xs are Ys'.

The problem with the supposed entailment ' $N(F, G)$ implies R' cuts deeper. $R$ is not 'part' of $N(F, G)$ in the way A is 'part' of 'A\&B', as David Lewis has pointed out. How then can we get the regularities out of $N$ ? $N$, we noted, necessitates R. Hence, it enforces $\mathrm{R}$, that is, it enforces that $\mathrm{F}$ and $\mathrm{G}$ are (always) co-instantiated. But there is nothing logically compelling in moving from ' $F$-ness necessitates $G$-ness' to 'All $F$ s are Gs'. ${ }^{6}$

The advocates of natural necessity have reacted to charges such as the above by taking necessity to be an immanent feature of nature, that is part of the basic metaphysical fabric of nature: the nature of properties, the essences of powers the like. On this view, there is no (external) law-making relation between properties in the world. It's not as if there are properties (first-order universals) and an external (second-order universal) relation of nomic necessitation between them, which enforces their coinstantiation and hence a regularity. Rather, the properties themselves are taken to be enough for the necessary connections there are in nature; the properties themselves are the law makers: the (immanent) regularity-enforcers.

Viewing properties as being embedded in a network of relations of entailments and exclusions simply transfers the problem of the (alleged) necessity of laws to a different territory: powers, dispositional essences and the like. What is thereby gained? Not much, I submit, when it comes to laws. For one, it is not clear any more whether there are or there are not laws. If the law-making relation is an internal relation, if, that is, it is fully determined by the properties involved in it, one may simply stay with the properties themselves and treat laws as summaries of the (alleged) necessary connections among properties. Indeed, the friends of metaphysical necessity have split up on this issue. There are those who think that natural laws are synopses of relations among modally laden powers. ${ }^{7}$ Others think that, simply, there are no laws- just modally laden powers (Mumford, 2004). It seems there is no fact of the matter as to whether there are laws of nature provided properties are modally-laden. If, however, it is cho-

\footnotetext{
${ }^{6}$ For some insightful discussion of the conceptual difficulties faced by the idea of 'contingent necessitation', see Bird (2007, 92-94).

${ }^{7}$ Here are some typical expressions of this view. Swoyer $(1982,218)$ : If we take account of the intrinsic nature of properties, then two (or more) properties "give rise to the law without the need for any additional relation" (...) "(T)he very natures of [F-ness] and [G-ness] make it impossible for there to be a world in which it is false [that All Fs are Gs]". Ellis: "According to essentialists, the laws of nature describe the essences of the natural kinds. They are not prescriptive of how things should behave, but descriptive of how they must behave, given their essential natures" $(2002,82)$. Bird: "Laws reflect the essences of properties"; "laws may be conceived of as a relation between properties, in which case the very nature of a potency provides what we want for a law, since its essence is a dispositional relation between a stimulus property and a manifestation property" (2007, 46, 64).
} 
sen that there are, it is no longer clear that they do anything other than just being there-all the (explanatory) work is done by the modally laden properties. ${ }^{8}$

But do modally laden properties do any real work? I will focus on only one issue, though more objections are available. ${ }^{9}$ Modally laden properties (aka powers or potencies) are supposed to enforce regularities; they ground the regularity there is in nature. But this is too quick. Assuming a lot about stable natures, powers might explain why things tend to behave in certain ways; or, better, why things would behave in a certain way, if the circumstances were right. Yet, tending to behave in a certain way (when the circumstances are right) does not entail the actual behaviour and, to be frank, it is consistent with any actual behaviour. There can be all the power in the world and no regularity in it. Differently put, it is only the regular exercise of powers (under certain circumstances and in the absence of contravening powers or factors) that yields anything like a regularity in nature; hence, no regularity in, no regularity out. So powers, in and of themselves, do not explain actual behaviour. ${ }^{10}$

The points made above were meant to rehash some rather well-known objections to views that there are external or internal relations of necessitation among properties in nature. The harder question is this: if there are no enforcers, what is it to be done? The cleanest way forward, I suggest, is an admission that the world does not have to be the way it is-it just $i s$. There are no further metaphysical facts or principles that enforce the way it is and make it impossible for it to be otherwise. Hence, laws are contingent: they are, but they might not be.

It should be immediately noted that denying the existence of enforcers (entailment; similarity; regularity) does not imply that anything goes (only that-almost-anything could go)! It implies, as it should, that laws are contingent (and not metaphysically necessary); that they do not have a grounding in metaphysically distinct layers of (internal or external) facts. In particular, it does not imply that there are no non-trivial actual relations between regularities in the world; that there are no actual objective relations of similarity and difference in the objects in the world.

The empiricist approach, as I am presently developing it, advocates a sparse metaphysical view of the world, according to which there are irreducible regularities in nature which, qua regularities, involve patterns of dependence among members of natural classes (natural properties) and which (patterns) underpin the modal relations there are between them. Hence, there is no need for an additional law-making relation of $a$ distinct metaphysical type-a regularity enforcer.

\footnotetext{
${ }^{8}$ Bird is aware of this problem. But he wavers between two views. The first is that laws simply stand proxy for potencies (modally-laden properties) and all explanatory work is done by properties (for if laws were to do some explanatory work over and above the properties, there would be an issue of overdetermination). The second is that laws 'inherit' some explanatory work from potencies (2007, 197-8).

${ }^{9}$ For more arguments against powers, see my (2006a) and (2006b).

10

For some insightful critique of powers, see Schrenk (2010).
}

Theoria 79 (2014): 9-27 


\section{Nomic Objectivism}

What I call the Sophisticated Regularity View of Laws (S-RVL) takes it that laws are: Regularities + differentia $(\mathrm{X})$. The key issue then is this: $\mathrm{X}$ should not be of a distinct metaphysical type; it should not be a regularity- or necessity-enforcer.

Historically and conceptually there have been two versions of S-RVL. Let's call the first Subjective S-RVL.

(SuS-RVL) $\mathrm{X}$ is a broadly subjective feature of the inquirers' attitude towards regularities.

What I will call Objective S-RVL, takes it what regularities constitute laws depends on broadly objective features of the world. Hence,

(OS-RVL) what makes a regularity a law (the differentia $\mathrm{X}$ ) is a broadly objective feature of the world.

There is an excellent candidate for OS-RVL, the Mill-Ramsey-Lewis view of laws. ${ }^{11}$ As is well-known, this view takes it the regularities that constitute the laws of nature are those that are expressed by the axioms and theorems of an ideal deductive system of our knowledge of the world, and in particular, of a deductive system that strikes the best balance between simplicity and strength. Simplicity is required because it disallows extraneous elements from the system of laws. Strength is required because the deductive system should be as informative as possible about the laws that hold in the world. Whatever regularity is not part of this best system, it is accidental: it fails to be a genuine law of nature. The gist of this approach is that no regularity, taken in isolation, can be deemed a law of nature. The regularities that constitute laws of nature are determined in a kind of holistic fashion by being parts of a structure.

This is a view that I still endorse, but in this paper, I want to sketch and defend what I take it to be a variant of the MRL-view, which relies on the notion of a (natural) pattern and builds (via the notion of the pattern) nomic objectivism into the regularity. Before we proceed, let me characterise this idea of 'nomic objectivism' and show how OS-RVL can be an objectivist view of laws.

We should take care to distinguish between regularity objectivism and power realism. ${ }^{12}$ Regularity objectivism is the view that regularities are objective in the sense that they would be there and continue to hold in the world even if there were no minds available. OS-RVL (and its variant I want to develop) is an objectivist view in this sense. Power realism is the view that there is regularity in the world because of the causal powers in the objects. OS-RVL clearly denies power-realism. But realism about laws should not be confused with power realism. The regularities that exist in the world are mind-independent. I have already noted that positing powers does not ipso facto yield regularities: there could be powers or forces or whatever without there being any regularity in the world. So power realism needs independent motivation, anyway.

\footnotetext{
${ }^{11}$ See my (2002) and (2009) for an analysis and defence. There are various objections against the objectivity of the Mill-Ramsey-Lewis approach, but, as I have argued in my 2009, the broadly objective character of this approach is not compromised.

12

Here I am modifying a useful distinction introduced by Costa (1989).
} 
There is a popular view that there is independent motivation for power realism. A key argument is based on the claim that OS-RVL leaves unexplained something that requires explanation, viz., the existence of regularity in nature. As noted already, the most immediate reply to this objection is that positing an extra layer of ontically distinct facts behind (or below) the regularities will itself be an unexplained explainer. The question 'what explains the regularity' is just pushed back: 'what explains the productive relation (or whatever)?'. There is not much gain here, because we should either take the presence of this extra layer of regularity-enforcing facts as selfexplanatory or we should just push back the terminus of explanation. As Wittgenstein (1953, \$304) aptly put it: "a nothing could serve just as well as a something about which nothing could be said". And that's exactly what the advocates of RVL should point out: one alleged mystery (the presence of regularity) is not explained by positing another mystery (a supposed productive relation or the like). As noted already, the presence of regularities in nature can be explained by appeal to other, more fundamental (and in this sense deeper), regularities. So their existence is not a matter of chance. But some regularities, the ultimate and fundamental ones, must be taken as brute: their presence admits of no further explanation. This does not imply that they are a matter of chance. Indeed, admitting that they are a matter of chance would amount to offering a further explanation - a chancy one - of their presence. For the friends of OS-RVL, the world consists of regularities all the way down - this is its metaphysical blueprint.

One might further wonder: even if we granted that OS-RVL is an objectivist approach to laws, wouldn't this be a thin metaphysics of laws? Obviously, it is thinner than one that explains (or grounds) the regularity in terms of relations of nomic necessitation and the like. From a metaphysical point of view, a regularity is a patterninvolving cosmic accident- there is no further reason why it holds. Well, that's basically right, but not entirely right. The kind of empiricism I want to defend denies that there is a regularity-enforcer that is of a distinct metaphysical type. It denies that the reason why a regularity holds should be sought in something other than the presence of regularity in nature; that the reason should be based on metaphysically more robust entities and facts about them. The regularities might well be grounded in further (more fundamental) regularities-this being the reason that they hold. Newton's laws provide the ground for Kepler's laws, and that's it!

\section{What is a Regularity?}

Regularities are real and mind-independent: they would exist as (perhaps very complicated) patterns among events even if there were no minds around. But there is a further worry. One may wonder: in what sense is a regularity real if only some part of it has been, as it were, actualised? If we have in our purview only past and present instances, in which sense is a regularity anything more than a synopsis of these instances?

I take this worry seriously because it forces us to think about the metaphysics of a regularity. A regularity is not a summary of what has happened in the past up until the present. Our evidence for the presence of a regularity in nature is always related to past 
(and present) instances, but the regularity itself is a universality-it extends to the present and the future; it covers everything under its fold. So one may naturally ask: what is a regularity, qua a truth-maker of a claim that has typically the form All Fs are Gs?

I want to claim that a regularity is best conceived as a perduring entity, since it cannot be said to be wholly present in different regions at different times. That is, a regularity has temporal and spatial parts. If we also accept eternalism (the view that past and future entities and times are no less real than the present ones), it is possible to conceive of the regularity sub specie aeterni. More specifically, a regularity should be conceived as having instances, where instances at other times and at other places are temporal and spatial parts of the regularity, and where (importantly and in addition) there is a pattern which unifies these instances. To repeat: it is important to be clear that we should distinguish the epistemic question of how we come to know the presence of a regularity, given that our evidence for it has always to do with past and present instances of it, from the metaphysical question of what kind of entity a regularity is.

Here is how I put things: A regularity $\mathrm{R}$ is constituted by the sum $\mathrm{S}$ of its instances, where instances at other times and at other places are temporal and spatial parts of the regularity. But, a regularity $\mathrm{R}$ is not identical with the sum $\mathrm{S}$ of its instances: there is more to regularity (viz., a pattern) than a collection of instances. To make this clear, we need to refer briefly to the issue of constitution vs. identity.

A flag is constituted by its molecules, but it is not identical with (the sum of) them: the two entities have different persistence conditions. A war-battered flag is still the flag that it was even though plenty of its initial molecules went missing! And a flag covered in blood is still the same flag even though molecules of a different kind are in it. The thought here is that entities are individuated by their persistence conditions; hence though an entity $\mathrm{R}$ might well be constituted by entities $\mathrm{S}$, it is not identical with their sum, if $\mathrm{R}$ has different persistence conditions than the sum of these entities $\mathrm{S}$. So, constitution is not identity. As Rudder Baker $(2007,32)$ has put it: "constitution is a relation of unity-unity without identity". She goes on to claim that "constitution is a relation between things of different primary kinds" (2007, 34). For my purposes, at least, we need not interpret this reference to kinds in a heavyweight way. It suffices to think of a regularity as being of a different kind than its instances, meaning that the regularity persists even when some of its instances cease to exist, or even if there were more instances. More importantly, I will claim, the regularity would have persisted even if some of its actual instances had not existed. So if we follow Rudder Baker, we should take constitution to be such that by virtue of it, new objects of new primary kinds are brought into being. Here again, this need not be read in a constructivist or idealist way. The 'new' object is as objective as its constituents.

There is a catch. The way 'constitution' is developed by Rudder Baker renders it a non-mereological notion. If an entity $\mathrm{X}$ cannot be identified with the mereological sum of its parts, then mereology is defied. However, as Rudder Baker makes it clear, even though it is right to say that if $\mathrm{X}$ is constituted by the sum of entities $\mathrm{Y}, \mathrm{X}$ is not identical to this sum, it is also right to add that sums are "the ultimate constituters" (2007, 185): an entity X might be constituted by the sum of entities Y, and yet 
commitment to $\mathrm{X}$ is a further commitment than simply to the mereological sum of its parts. Hence, she claims that her view "can make peace with mereology" $(2007,186)$.

I want to suggest that there is a way to reconcile mereology with ontological novelty. In this I am following the significant work by Ingvar Johansson (1998; forthcoming). Mereology is based on the notion of proper part (' $Y$ is proper part of $X^{\prime}$ ) and this notion is governed by three axioms: it is irreflexive, asymmetric and transitive. There is a principle called 'weak supplementation' (WS) according to which: if a whole has a proper part, it has also another proper part that is disjoint from the first. If we want to preserve the idea that constitution is compatible with ontic novelty, we need to explore the intuition that, occasionally at least, the whole is more than the sum of its constituent parts - where the term 'sum' is used here in an informal and ordinary way, of course.

Take the following symbol :-). It's called 'smiley' and is used widely to communicate certain feelings in electronic correspondence; we take it to mean something and by virtue of this it plays a specific role in our written communication. Its constituent parts are - . ) together with a certain spatial arrangement (that is a network of specific spatial relations among the parts).

Smiley supervenes on its parts: there is no difference in the whole, without some difference in the parts. In fact, -): has the same constituent parts in a different spatial arrangement; hence it is a different entity, which cannot be properly used to convey the intended message of Smiley. Notably, Smiley and the sum of its constituent parts have different persistence conditions. If some pixels are removed, as in the image below, we still have a Smiley and the intended message is still conveyed, though part of the constituent bracket is chipped off.

Can we, without leaving mereology, preserve the intuition that there is more to Smiley than the sum (in the ordinary sense) of its constituent parts, where this more is the meaning it communicates? Here is where Johansson's ideas can help. Call Smiley R; and call $\mathrm{S}$ the sum of its constituent parts (i.e., - . .) and their specific spatial arrangement). $\mathrm{S}$ and $\mathrm{R}$ coincide spatially and there is a sense in which $\mathrm{S}$ constitutes $\mathrm{R}$, being the sum of R's spatial constituent parts. But there is also a non-spatial part of Smiley R, viz., in this case the 'happy face' meaning conveyed. S (the constituent-parts-in-their-spatialrelations) is a proper part of $\mathrm{R}$ and there is another part of $\mathrm{R}$ that is not a (spatial) constituent of $\mathrm{R}$. The principle of weak supplementation (see above) is satisfied; hence, mereology is not defied. Let's call this further part W. Clearly, R is not identical with S, though it is constituted by it. But R is identical with the mereological sum of $\mathrm{S}$ and $\mathrm{W}$. W is a supervening entity, which, nonetheless, is a proper part of $\mathrm{R}$, without being a (spatial) constituent part of $\mathrm{R}$.

It is a matter of indifference to me how exactly we describe the situation at hand, provided we are clear on what has been going on. We may reserve the technical term 'composition' for the operation according to which parts form a whole and claim that constitution is mereological composition (where some of the parts are not spatial). 
Or we may say that there are proper parts which are not constituent parts of a whole, since they are proper parts which are not spatially distinct from the constituent parts. The key point, I take it, is that there is ontic novelty grounded in the existence of nonspatial parts of a whole. ${ }^{13}$

What is the connection of all this with the metaphysical status of regularities? Here is the suggestion. A regularity $\mathrm{R}$ is the mereological sum of its parts and yet it is more than the sum (in the colloquial sense) of its spatio-temporal constituents (that is, its instances). Call $\mathrm{S}$ the totality of the instances (spatio-temporal parts) of the regularity. $\mathrm{S}$ is a proper part of $\mathrm{R}$ and yet (according to the weak supplementation principle) there is another proper part of $\mathrm{R}$ which is not a spatial constituent of $\mathrm{R}$. Call this P. Hence, $\mathrm{R}=\mathrm{S}+\mathrm{P}$. What is this further proper part P? I claim: The pattern that unifies the regularity. ${ }^{14}$

I think it's generally acceptable that the constituent (spatio-temporal) parts of a regularity are its instances. Intuitively, they are the objects that 'fall under' the regularity with their properties. For instance: ravens; the orbit of the Earth (and of the other planets) around the sun; a neutron decaying (beta-decay) etc. But what is a pattern?

\section{Patterns as Parts of Regularities}

Surprisingly, though there is substantial philosophical and mathematical literature on this issue, the notion of pattern is not defined. Dennett (1991) famously relied on behavioural patterns to ground ascriptions of propositional attitudes and their explanation/prediction. He took it that "A pattern exists in some data-is real-if there is a description of the data that is more efficient than the bit map, whether or not anyone can concoct it" $(1991,34)$. So a pattern in some data is a compressed description of the information encoded in the data. Resnik $(1997,202)$ takes it that patterns are structures. Hence, he notes that "a pattern consists of one or more objects (...) that stand in various relationships", where the objects in the pattern are "positions" (1997, 202-3). By doing this, Resnik intends to preserve the intuition that different concrete

${ }^{13}$ We may usefully appeal to the notion of 'form' and claim that a whole has both formal and material parts. An object, then, is the sum of its material and formal parts and the weak supplementation principle is satisfied.

14 A perceptive referee noted: "The weak supplementation principle says that, if $\mathrm{S}$ is a proper part of $\mathrm{R}$, then there is another proper part of R. But we could be of the view that there is no further proper part of R. We could then infer, by modus tollens, that $\mathrm{S}$ isn't a proper part of $\mathrm{R}$, but that $\mathrm{S}$ is an improper part of $\mathrm{R}$, or that $\mathrm{S}$ is just identical to $\mathrm{R}$. So the weak supplementation principle on its own doesn't justify the claim that there is a proper part, P, of R that is distinct from S. (It only does so when combined with the further premise that $\mathrm{S}$ is a proper part of $\mathrm{R}$. But some argument for this claim is needed)." I agree with this line of reasoning, but I am not committed to the view that the weak supplementation principle is enough to justify the claim that the pattern is a proper part of the regularity. The Smiley example is meant to show how we may conceive of a supervening entity (the 'meaning' of Smiley) as a proper part of a whole. I have only used this analogy to motivate the claim that the pattern exemplified by a regularity can be seen in a similar way. That there is a pattern in addition to the instances of the regularity is independently motivated since it is meant to be explanatory of various features of a regularity, e.g, its robustness; its unity; its modal force; its 'governing' its instances. 
arrangements of things may instantiate the same pattern. Ladyman and Ross (2007, 119) rely on Dennett's real patterns and aim to defend the thesis that "what exists are ('real') patterns". But they also distinguish between structure and pattern based on the thought that talk of structures is talk in the formal mode of speech, whereas talk of patterns is in the material mode. Then, they aim to show how worldly patterns can be represented by mathematical structures. McAllister (2011) looks into patterns in empirical data and how they can provide evidence for stable structures in the world. $\mathrm{He}$ rightly points out that a pattern in a string of data is an additive component of this string, and, following Grenander, he claims that a pattern "is what remains once some other component has been subtracted, item by item, from the data-set" (2011, 75). Indeed, Pattern theory is a well-developed mathematical framework for describing patterns as structures regulated by (combinatorial) rules and operations.

My own perspective is somewhat more metaphysical. A pattern certainly involves compressed information about the instances that share it and it is certainly expressible in structural terms. But what is it? Aiming for a notion of pattern which is as general and inclusive as possible, I claim the following: a pattern is a repeatable and recurring network of stable similarities and differences among various entities. Repeatability is essential. Take a simple regularity such that all ravens are black. Though simple, it is instructive when it comes to the notion of a pattern. The instances of the regularity (that is, a raven being black) are not repeated. They might endure in time (e.g., a raven might live for 15 years); they might move about in space. Still, this raven being black is a single spatio-temporal case which encodes no repetition. What recurs is the pattern among the instances, viz., similarity in colour (and various other things of course) among the ravens; that is, the blackness of ravens. It is this recurring pattern that acts as a principle of unity of the various instances. All ravens resemble each other when it comes to colour (and other respects too, of course) and this (stable and repeatable) resemblance constitutes the pattern which, alongside the instances, make up the regularity.

In light of what was said above, the pattern is a proper part of the regularity, though, unlike the instances, it is not a spatial constituent of it. However, the pattern supervenes on the instances: there cannot be a change in the pattern without a change in some instances. By the same token, the regularity is not reducible to its instances, precisely because there is the pattern in it too. The regularity persists even when some of its instances cease to exist. The presence of the unifying principle- the patternmakes it possible that if some of the actual instances of the regularity had not existed, the regularity would still be there, provided other of its instances exist (and have existed). The regularity could not have existed without instances; the pattern cannot be there without entities to be a pattern in. But the regularity would have existed even if some of the actual instances would have not existed.

The idea of a pattern as a repeatable and recurring network of stable similarities and differences among various entities is easily applicable to more sophisticated cases. The elliptical orbit is a pattern in the motion of the planets: it is a stable and repeatable similarity in planetary motions around the sun. Further examples can be generated at will. 
In order to warn off a misinterpretation of what I am trying to say, I should stress that my point is not epistemological. I am not concerned with the evidence we might have for the existence of a pattern in nature-this will always be evidence concerning past similarities and repetition. My point, if I may repeat, is meant to be metaphysical: what a regularity is, irrespective of how we come to know it. There is no regularity without a pattern and insofar as a pattern is missing there is no regularity even if the evidence so far might lead us to think that there is. That there is a pattern in the instances of a regularity is, then, as objective a feature of a regularity as that it has instances.

Having said this, it should be added that the very idea of a pattern as an element of a regularity can explain how some generalisations are more projectible (given the evidence) than others. If we have reasons to believe that there is a pattern among the instances of an alleged regularity, we can project it to the future or to unobserved instances. I am not therefore claiming that we can solve the problem of induction by an appeal to patterns. But an appeal to patterns can help us explain why we take it that some inductive projections are safer or more warranted than others. It can also help us explain why there is no fixed threshold of observed instances after which we are entitled to generalise. The evidence (observational and theoretical) for the existence of a pattern might be strong enough just after a few instances only. Finally, an appeal to patterns can explain why warranted generalisations can have (some) modal force. As noted already, patterns are supposed to have a certain robustness over and above the instances of the regularity: they can be there even if some of the actual instances of the regularity did not exist.

Sellars $(1956,268)$ pointed out that when laws are taken to be regularities, they are those regularities that are characterised by "neck-sticking-out-ness", where this characteristic is captured in the subjunctive mood: "If this were an A-situation, it would be accompanied by a B-situation'. The counterfactual force of a law then can be seen as a 'contextual implication' of a law-statement. This idea of 'contextual implication' is captured by the supposition view of counterfactuals, as this was developed by John Mackie (1973). According to this view, to assert something like $\mathrm{X} \rightarrow \mathrm{Y}$ is to assert $\mathrm{Y}$ within the scope of the supposition that $X$. In other words, we suppose $\mathrm{X}$ and then we envisage various possibilities and consequences. The supposition view takes it that counterfactuals are not truths about possible words but ways to express an attitude towards a possible state of affairs made within the scope of a supposition. The notion of the pattern strengthens this view since it can ground the thought of the "neck-sticking-outness" of regularities. The presence of the pattern in a regularity grounds the supposition that if there were a further $\mathrm{X}$, it would be $\mathrm{Y}$. For the addition of the supposition that there is an extra $\mathrm{F}$ does not defeat the grounds for accepting the presence of the regularity insofar as there is a pattern in it. ${ }^{15}$

${ }^{15}$ It can argued, however, that the notion of the pattern would work equally well under the more popular (and perhaps more plausible) 'possible worlds' semantics for counterfactuals. It seems plausible to say that the most similar worlds in which there is an extra raven in existence are worlds in which the 
The key idea so far is that the persistence conditions of the regularity include the stability of a pattern. So the regularity displays the unity of a pattern, where the pattern may be thought of as the form of the regularity. This way of viewing things has a number of advantages, which I will only highlight at present.

- Patterns may occur within other patterns.

- There can be higher-level patterns.

- Patterns can be abstract/structural.

- Different concrete arrangements of things may instantiate abstract patterns.

These characteristics can explain why some regularities can be nested within others or why some regularities can share structural/mathematical form.

\section{What is a Law of Nature?}

Not all regularities are laws of nature. At the same time, a regularity involves a pattern 'over and above' the sum of its spatio-temporal instances. My suggestion is this: a law of nature is a regularity that is characterised by the unity of a natural pattern. So there is a sense in which since a regularity already includes a pattern, there is no extra element that renders it a law of nature. But there is also a sense in which the pattern should be of a certain kind if the regularity is law of nature; the kind being 'natural'. This way to proceed has the advantage that the distinction between the so-called accidental regularities is a function of the naturalness of the pattern involved in a regularity.

Natural patterns involve natural properties. How exactly a natural property is characterised is not a very straightforward issue (at least for someone who is not an essentialist), but we might follow Lewis's (1984) lead and take it that natural properties (or classes) are distinguished from each other by objective similarities and differences in nature. This notion of naturalness is hard to define-Lewis takes it as an unanalysed, yet indispensable, primitive. According to Lewis, the inventory of perfectly natural classes (properties) is (or will be) delivered by fundamental physics. But even allowing for perfectly natural properties, naturalness, as Lewis himself agues, is a matter of degree. Some properties are more natural than others (say, mass or charge relative to colours and colours relative to gruesome properties). But the very idea of degrees of naturalness implies that, as we move away from the 'perfectly natural' end of the natural-unnatural continuum and towards the 'highly unnatural' (disjunctive, gerrymandered) end of it, similarity judgements become less objective and more dependent on us (our categories and classificatory schemes).

The undeniable implication is that since patterns may be more or less natural according to the degree of naturalness of the properties involved in them, laws of nature become more or less robust: more or less (in)dependent of our own criteria of similarity and difference. As we go down to the level of atoms and elementary particles and their properties, this dependence on our classificatory practices is diminished. At that level, there are objectively circumscribed natural properties: not only are the

black ravens pattern is preserved, and so that extra raven is black. (I thank a perceptive reader of the paper for this point). 
similarities and differences between types of elementary particles objective, but also the respects and degrees in which they are similar and different are fixed by the way the world is.

Be that as it may, it is to be noted that according to the conception outlined presently, laws are natural-pattern-involving regularities and yet there is no patternenforcer (of distinct metaphysical type). A pattern needs nothing external to sustain it or enforce it; it is itself, so to speak, the law-maker.

Just because the distinction between laws and accidents is a matter of degree it does not mean that it is arbitrary. To see that it is not let us add a further element to the story outlined so far, which among other things, will show how the approach canvassed here is a variant of the MRL-view of laws. Patterns, we noted above, can occur within other patterns. Hence there can be non-trivial relations among patterns. Gravitational orbits occur within patterns of conic sections. The DNA molecule has a wellknown double helix pattern, within which there is another pattern: the way the nucleic acids are configured in the double helix is a pattern within a pattern. Chemical reactions fall under patterns which involve further bond-forming and bond-breaking patterns. Generally, patterns in nature do not live in isolation. They form networks; they are related to other patterns; they repeat themselves in various and diverse phenomena. Periodic motions, for instance, form certain period patterns that are exemplified in various phenomena; branching patterns are exemplified in a variety of cases like trees and arteries.

Though this claim requires more development than I can offer here, it suggests that it may well be a fact about the world we live in that the regularities there are in it form, objectively, a network underpinned by interlocking and repeatable natural patterns. In other words, the world bas a regularity structure, in which, by virtue of their patterns, regularities stand in certain relations to each other. These relations are possible because the patterns that characterise the regularities form a network: they occur within other patterns and they stand to definite relations to other patterns.

If this is broadly right, then the proposed account is indeed a variant of the MillRamsey-Lewis approach with the further advantage that the best system is the one that captures the network of regularities (the network of natural patterns) that there is in the world.

\section{Concluding Thoughts}

There are various loose ends that need to be tied, if the account I have put forward is to be thoroughly developed. But I trust the outline is clear enough to suggest that it is worth pursuing. Among the many objections that can be levelled against it, two stand out and I want to address them, even if partially and quickly.

The first objection is that the notion of the pattern might well introduce a suspectto-empiricism reliance on universals, since patterns could be universals. Though I feel the force of this objection, I reply that though they could be, they need not be. Actually, it is perfectly legitimate to think of patterns as particularised tropes and I am inclined to conceive them this way. 
The second objection is that the conceptual machinery employed in this paper to analyse regularities might well be too much for a proper empiricist to swallow. To this I reply that it is an open question what proper empiricism implies and what not. If metaphysics is inevitable, I prefer to follow Herbert Feigl's advice: “if this is metaphysics, make the least of it". How little is the least will depend on the explanatory issue at hand. I trust that the metaphysical inflation required for a proper empiricist understanding of regularities was minimal, though not negligible.

To sum up: There can be regularity in the world without regularity-enforcers. A regularity involves the unity of a pattern, apart from its instances. Laws of nature are those regularity that involve the unity of a natural pattern. Natural patterns do not exist in isolation from each other but form a network.

\section{REFERENCES}

Ayer, Alfred Julius. 1963. What is a Law of Nature? In The Concept of a Person and Other Essays, London: Macmillan.

Bird, Alexander. 2007. Nature's Metaphysics: Laws and Properties. Oxford and New York: Oxford University Press.

Costa, Michael J. 1989. Hume and Causal Realism. Australasian Journal of Philosophy 67: 172-90.

Dennett, Daniel C. 1991. Real Patterns. The Journal of Philosopby 88: 27-51.

Ellis, Brian. 2002. The Philosophy of Nature: A Guide to the New Essentialism. Chesham: Acumen.

Kant, Immanuel. 1787. Critique of Pure Reason. Norman Kemp Smith (trans.) (1965), New York: St Martin's Press.

Kneale, William. 1949. Probability and Induction, Oxford: Clarendon Press.

Lewis, David. 1984. Putnam's Paradox. Australasian Journal of Philosophy 62: 221-36.

- 1991. Parts of Classes. Oxford: Blackwell.

Johansson, Ingvar. 1998. Pattern as an Ontological Category. In Formal Ontology in Information Systems (FOIS 1998), edited by Guarino Nicola. Amsterdam: IOS Press, 86-94.

—. Forthcoming. Natural Science and Mereology. In Handbook of Mereology, edited by Hans Burkhardt, Guido Imaguire, Johanna Seibt. Munchën; Philosophia Verlag.

Ladyman, James and Don Ross. 2007. Every Thing Must Go: Metaphysics Naturalized. Oxford: Oxford University Press.

Mackie, John Leslie. 1973. Truth, Probability and Paradox. Oxford: Clarendon Press.

McAllister, James W. 2011. What do Patterns in Empirical Data Tell us About the Structure of the World? Synthese 182: 73-87.

Psillos, Stathis. 2002. Causation and Explanation. Chesham: Acumen.

- 2006a. What do Powers do when they are not Manifested? Philosophy and Phenomenological Research 72: 135-56.

-. 2006b. Critical Notice: Laws in Nature. Metascience 15: 437-69.

- 2009. Regularity Theories. In Oxford Handbook of Causation, edited by Helen Beebee, Peter Menzies and Christopher Hitchcock. Oxford: Oxford University Press, 131-57.

—. 2011. Choosing the Realist Framework. Synthese 190: 301-316

Resnik, Michael. 1997. Mathematics as a Science of Patterns. Oxford: Oxford University Press.

Rudder Baker, Lynne. 2007. The Metaphysics of Everyday Life: An Essay in Practical Realism. Cambridge: Cambridge University Press.

Russell, Bertrand. 1956. Logic and Knowledge, London: George Allen and Unwin.

Schrenk, Markus. 2010. The Powerlessness of Necessity. Nous 44: 725-39.

Sellars, Wilfrid. 1956. Counterfactuals, Dispositions, and the Causal Modalities. In Concepts, Theories and the Mind-Body Problem (Minnesota Studies in the Philosophy of Science, vol. II), edited by Herbert Feigl, Michael Schriven and Grover Maxwell. Minneapolis: University of Minnesota Press, 225-308.

Swoyer, Chris. 1982. The Nature of Natural Laws. Australasian Journal of Philosophy 60: 202-23.

Wittgenstein, Ludwig. 1953. Philosophical Investigations. Oxford: Blackwell. 
Stathis Psillos joined the Rotman Institute of Philosophy and the Department of Philosophy of the University of Western Ontario in 2013, where he holds the Rotman Canada Research Chair in Philosophy of Science. He joined the Department of Philosophy and History of Science in the University of Athens, Greece, in 1999, and he is the Principal Investigator of the Research Programme: Aspects and Prospects of Realism in the Philosophy of Science and Mathematics (APRePoSMa). In 2008 he was elected member of I'Academie Internationale de Philosophie des Sciences (AIPS). He was the president of the European Philosophy of Science Association (2007-2009) and has been the editor of the journa Metascience since 2009. He is the author and editor of 8 books and over 100 papers and reviews in learned journals and edited collections, mainly on scientific realism, causation, explanation and the history of philosophy of science.

Address: Rotman Institute of Philosophy \& Department of Philosophy, University of Western Ontario London, Ontario N6A 5B8, Canada. E-mail: spsillos@uwa.ca 